\title{
Social Story untuk Menurunkan Perilaku Agresif Anak dengan Retardasi Mental
}

\section{Social Story to Reduce Aggressive Behavior of Children with Mentally Retarded}

\author{
Novia Solichah \\ Fakultas Psikologi UIN Maulana Malik Ibrahim Malang \\ noviasolichah@uin-malang.ac.id
}

\begin{abstract}
Abstrak
Tujuan dari penelitian ini adalah untuk menganalisis efektivitas social story untuk mengurangi perilaku agresif pada anak dengan retardasi mental. Jenis penelitian yang digunakan adalah penelitian eksperimen yang berbentuk single subject research dengan desain grafik A-B-A'. Subjek dalam penelitian ini adalah seorang anak dengan retardasi mental ringan (WISC, IQ: 69), berjenis kelamin perempuan di sebuah Sekolah Dasar. Subjek memiliki kecenderungan perilaku agresif,. Subjek kesulitan untuk memulai berinteraksi dengan orang lain dengan guru maupun teman, subjek sering menendang, memukul, dan menggigit orang lain pada saat subjek berinteraksi dengan orang lain. Data diukur menggunakan frekuensi untuk melihat berapa kali subjek melakukan tindakan memukul, menendang, dan menggigit orang lain. Metode pengumpulan data menggunakan observasi langsung. Secara kuantitatif, hasil penelitian menunjukkan bahwa intervensi yang dilakukan mampu menurunkan perilaku memukul, menendang, menggigit. Dengan kata lain, social story mampu menurunkan perilaku agresif anak dengan retardasi mental.
\end{abstract}

Kata kunci: social story, interaksi social, perilaku agresif, anak dengan retardasi mental

\begin{abstract}
This study aims to analyze the effectiveness of social stories to reduce aggressive behavior in children with mentally retarded. The type of research used is experimental research in the form of single subject research with $A-B-A$ 'graphic design. The subject in this study was a child with mild mentally retarded (WISC IQ: 69), female in an elementary school. The subject has a tendency towards aggressive behavior. The subject has difficulty starting to interact with other people with teachers and friends, the subject often kicks, hits, and bites other people when the subject interacts with other people. The data was measured using frequency to see how many times the subject did the action of hitting, kicking, and biting another person. The data collection method uses direct observation. Quantitatively, the results of the study show that the interventions can reduce hitting, kicking and biting behaviors. Social stories can reduce the aggressive behavior of children with mental retardation.
\end{abstract}

Keywords: social story, social interaction, aggressive behavior, children with mentally retarded

\section{Pendahuluan}

DSM V (DSM-5, 2013), menjelaskan disabilitas inteletual merupakan gangguan yang muncul di masa perkembangan, pada aspek intelektual dan rendahnya fungsi adaptif dalam domain konseptual, sosial, serta praktis. Untuk penegakan diagnosa, beberapa kriteria yang harus terpenuhi adalah sebagai berikut: 1) Defisit pada fungsi intelektual seperti penalaran, pengambilan keputusan, perencanaan, berfikir abstrak, penilaian, pembelajaran akademis, serta belajar berdasarkan pengalaman yang 
dikonfirmasikan dengan asesmen klinis serta tes intelegensi yang terstandar. 2) Defisit dalam fungsi adaptif yang menghasilkan kegagalan dalam memenuhi standar perkembangan serta sosial budaya untuk kemandirian dan tanggung jawab sosial tanpa dukungan yang berkelanjutan, keterbatasan fungsi adaptif akan membatasi fungsi pada beberapa aktivitas dalam kehidupan sehari-hari seperti komunikasi, partisipasi sosial, serta kemandirian hidup pada beberapa setting lingkungan seperti rumah, sekolah, pekerjaan, dan komunitas. 3) Defisit dalam satu area baik itu secara konseptual, sosial atau praktis dapat memenuhi syarat untuk penegakan diagnosa. Kemunculan defisit pada fungsi intelektual dan adaptif terjadi selama periode perkembangan.

APA (American Psychology Association) membuat klasifikasi mengenai penyandang disabilitas intelektual yang hingga sekarang digunakan oleh beberapa sekolah seperti mild (ringan), moderate (sedang), severe (parah), dan profound (sangat parah). 4 klasifikasi tersebut dibuat berdasarkan tingkat kecerdasan atau skor IQ (Hallahan, 2006). DSM IV TR juga membedakan tingkat disabilitas berdasarkan fungsi intelektualnya (DSM-5, 2013): 1) Mild Mental Retardation (IQ 50-55 hingga 70). 2) Moderate Mental Retardation (IQ 35-40 hingga 50-55). 3) Severe Mental Retardation (IQ 20-25 hingga 35-40). 4) Profound Mental Retardation (IQ dibawah 20-25). 5) Mental Retardation, severity unspecified, istilah yang digunakan jika terdapat anggapan yang kuat terjadinya disabilitas intelektual.

Ciri anak dengan retardasi mental mild merupakan mampu didik, Mereka tidak memperlihatkan kelainan secara fisik mencolok, meski perkembangan fisiknya sedikit terlambat dari pada anak ratarata. Tinggi serta berat tubuh mereka tidak berbeda dengan kanak-kanak lain, namun bersumber pada hasil observasi mereka kurang perihal kekuatan, kecepatan, serta koordinasi, dan kerap mempunyai permasalahan kesehatan (Mangunsong, 2009). Mereka masih dapat bersekolah di sekolah umum, walalupun lebih rendah daripada kanak-kanak pada umumnya. Umumnya rentang atensi mereka pula pendek sehingga susah berkonsentrasi dalam jangka waktu yang lama. Mereka terkadang menghadapi frustasi kala diminta berperan secara sosial ataupun akademik seusia mereka, sehingga tingkah laku mereka dapat jadi tidak baik, misalnya acting out dari kelas, berperilaku agresif, serta tidak mau melaksanakan tugas kelas (Mangunsong, 2009).

Pada aspek perkembangan social, anak tunagrahita cenderung sulit mendapatkan teman dan mempertahankan pertemanan, karena pertama, mereka tidak tahu bagaimana memulai interkasi sosial dengan orang lain. Kedua, ketika mereka tidak sedang berusaha untuk berinterkasi dengan orang lain, mereka mungkin menampilkan tingkah laku yang membuat teman-teman menjauh, misalnya karena perhatian yang tidak fokus dan mengganggu. Pada aspek regulasi diri, anak dengan retardasi mental mengalami kesulitan untuk mengatur tingkah lakunya sendiri (Ageranioti-Bélanger et al., 2012). Banyak studi terkait individu dengan intelektual disabilitas memiliki hambatan dalam kemampua social dan butuh untuk diberikan perlakuan sistematis.(Gül, 2016)

Perilaku agresif yang dilakukan oleh anak dengan retardasi mental disebabkan karena deficit yang ia miliki, dan membutuhkan untuk penanganan professional (Brulle, 1981). Salah satu alasan perilaku agresif yang muncul pada anak dengan disabilitas intelektual ini harus segera ditangani adalah karena hal ini bisa menyakiti dirinya sendiri maupun orang lain, seperti perilaku melempar benda-benda dan dapat menimbulkan masalah serius (Brulle, 1981).

Karakteristik subjek penelitian kali ini, seorang anak dengan retardasi mental ringan, berjenis kelamin perempuan di sebuah Sekolah Dasar. Subjek memiliki kecenderungan perilaku agresif,. Subjek kesulitan untuk memulai berinteraksi dengan orang lain dengan guru maupun teman, subjek sering menendang, memukul, dan menggigit orang lain pada saat subjek berinteraksi dengan orang lain.

Perilaku agresif yakni perilaku baik secara fisik ataupun mental, yang bertujuan menyakiti maupun melukai orang lain (Berkowitz, 2003). Akibat dari perilaku agresif, anak hendak menghadapi kesulitan dalam melaksanakan interaksi dengan anak lain. Kokko, Pulkkinen, Huesmann, Dubow, serta Boxer (Kokko et al., 2010) perilaku agresif yang muncul saat anak telah merambah dunia remaja dan dewasa akan cenderung lebih berat. Ali \& Utami (2013) menjelaskan bila perilaku agresif di masa kanak-kanak ialah faktor resiko bagi perkembangan di masa selanjutnya. Perilaku agresif tidak bisa dibiarkan serta butuh usaha dalam mengendalikannya agar tidak timbul akibat negatif pada anak yang bisa berlanjut sampai usia dewasa (Papalia et al., 2010).

Ada banyak literature di mana individu dengan disabilitas intelektual menunjukkan defisit dalam ketrampilan sosial, yang mana menujukkan adanya kebutuhan untuk mengajarkan ketrampilan sosial secara sistematis (Gül, 2016). Pada penelitian Gul (2016) diketahui bahwa penggunaan intervensi yang terdiri dari pemodelan video yang disajikan oleh komputer dan cerita sosial (social stories) kepada individu dengan disabilitas intelektual efektif untuk meningkatkan kemampuan dalam keterampilan 
sosial. Hasil penelitian menunjukkan bahwa individu dengan disabilitas intelektual memperoleh ketrampilan sosial dengan akurasi $100 \%$, mempertahankan ketrampilan sosial dari waktu ke waktu, dan dapat digeneralisasikan di banyak setting, kondisi, dan orang-orang (Gül, 2016).

Metode yang sedang terkenal dalam dunia Pendidikan berkebutuhan khusus adalah menggunakan cerita sosial (Tarnai \& Wolfe, 2008). Sebuah cerita sosial (social story) merupakan cara pengajaran yang tepat untuk mengajarkan ketrampilan sosial dan perilaku anak atau yang berkaitan dengan hambatan yang melekat pada individu dengan hambatan intelektual.

Quirnbach, dkk (2008) juga mengungkapkan bahwa cerita sosial merupakan cara yang efektif untuk mengajarkan perilaku sosial yang pantas dan sesuai dengan norma. Cerita sosial merupakan suatu metode yang baik disebabkan sifatnya yang visual, langsung pada situasi spesifik, menyediakan informasi yang eksplisit dan pembelajaran bersifat jangka pendek namun memiliki efek jangka panjang (Quinbach, dkk 2008). Berdasarkan hal tersebut peneliti ingin meneliti mengenai efektivitas social story untuk mengurangi perilaku agresif anak dengan retardasi mental.

\section{Metode Penelitian}

Metode dalam riset ini adalah single-case experimental design. Desain multiple baseline cross variables bisa digunakan kala sesuatu intervensi yang diperkirakan mampu mengganti perilaku yang memberikan dampak terhadap 2 ataupun lebih sasaran perilaku (Latipun, 2011). Identitas ataupun ciri pada subjek penelitian kali ini, seorang anak dengan retardasi mental ringan, berjenis kelamin perempuan di sebuah Sekolah Dasar. Subjek memiliki kecenderungan perilaku agresif,. Subjek kesulitan untuk memulai berinteraksi dengan orang lain dengan guru maupun teman, subjek sering menendang, memukul, dan menggigit orang lain pada saat subjek berinteraksi dengan orang lain.

Desain eskperimen yang digunakan merupakan desain A-B-A' (Latipun, 2011). Dimana A1 ialah fase baseline (A). Tahap intervensi (B). A2 (baseline 2) merupakan fase sehabis intervensi (Sunanto, dkk, 2005). Analisis data memakai analisis visual dalam kondisi dan analisis visual antar kondisi. Alat pengumpulan data dalam riset memakai observasi pada tahap A-B-A'. Prosedur riset yang dilakukan dengan menetapkan perilaku yang hendak diganti, setelah itu menentukan intervensi untuk mengubah perilaku. Perilaku yang hendak diganti adalah perilaku memukul, menggigit, serta menendang. Pemberian intervensi serta observasi dilakukan dikala Aktivitas Belajar Mengajar (KBM).

\section{Hasil Penelitian}

Tujuan dari penelitian ini adalah untuk membantu mengurangi perilaku agresif pada anak dengan retardasi mental melalui social story. Peneliti melakukan observasi pada perilaku agresif anak yang muncul selama di kelas, dan mencatat jumlah munculnya perilaku menendang, memukul, menggigit. Peneliti mencatat berapa kali subjek menendang, memukul, dan menggigit. Penelitian ini menggunakan desain single subject research, dan dilakukan selama 12 sesi. Berikut data perilaku menendang, memukul, menggigit selama 12 kali.

Tabel 1. Rekapitulasi data frekuensi perilaku subjek

\begin{tabular}{|c|c|c|c|c|c|c|c|c|c|c|c|c|}
\hline \multirow{2}{*}{ Perilaku Subjek } & \multicolumn{4}{|c|}{ Fase Baseline (A1) } & \multicolumn{4}{|c|}{ Fase Intervensi (B) } & \multicolumn{4}{|c|}{ Fase Baseline (A2) } \\
\hline & 1 & 2 & 3 & 4 & 5 & 6 & 7 & 8 & 9 & 10 & 11 & 12 \\
\hline Perilaku menendang & 5 & 5 & 5 & 4 & 3 & 2 & 2 & 1 & 1 & 0 & 0 & 0 \\
\hline Perilaku memukul & 5 & 6 & 7 & 7 & 2 & 1 & 1 & 1 & 0 & 0 & 0 & 0 \\
\hline Perilaku Menggigit & 3 & 4 & 4 & 5 & 2 & 1 & 0 & 0 & 0 & 0 & 0 & 0 \\
\hline
\end{tabular}

Sumber : Data Primer, 2021.

Tabel 1 menunjukkan perolehan angka untuk perilaku subjek menendang, memukul, menggigit, selama 12 sesi menunjukkan perubahan frekuensi. Perilaku menendang, memukul, menggigit subjek selama 12 sesi mengalami penurunan, berikut visualisasi dari grafik perilaku menendang, memukul, dan menggigit. 


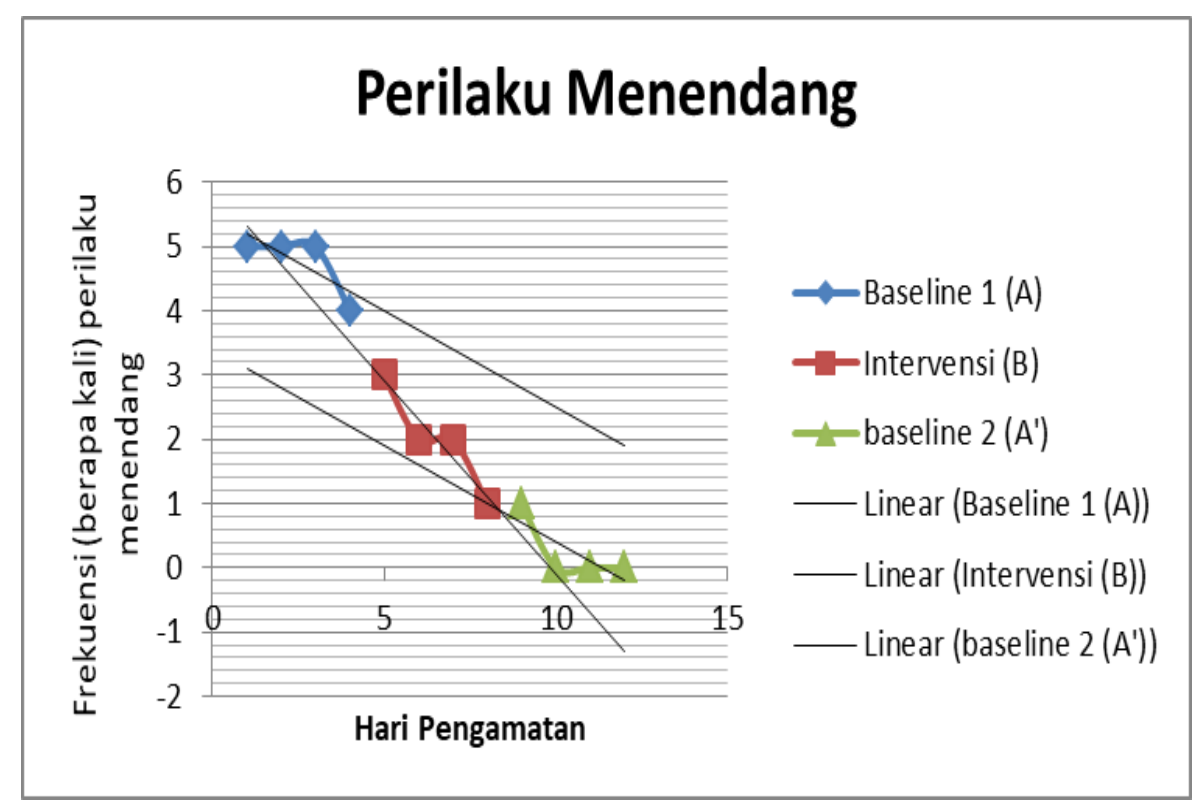

Sumber : Data Primer, 2021.

Gambar 1. Analisis visual perilaku menendang subjek fase A1, B, A2

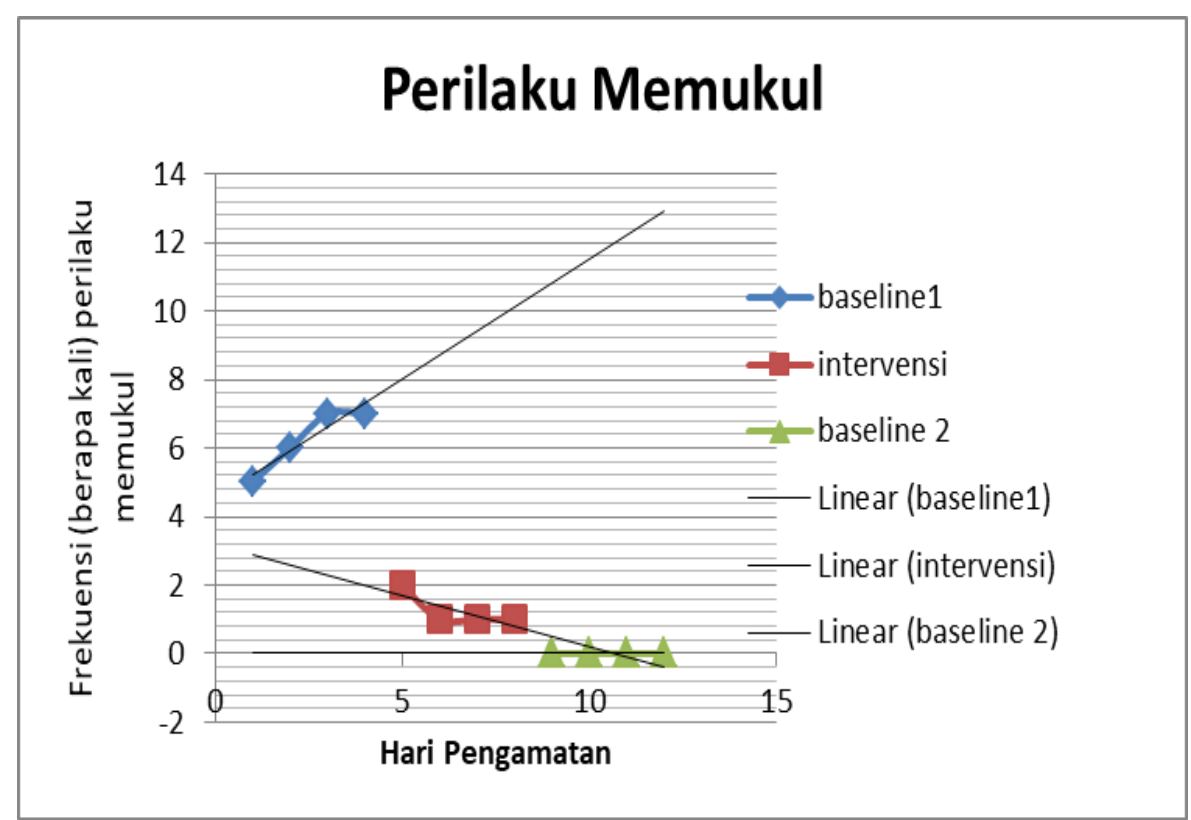

Sumber : Data Primer, 2021.

Gambar 2. Analisis visual perilaku memukul subjek fase A1, B, A2 


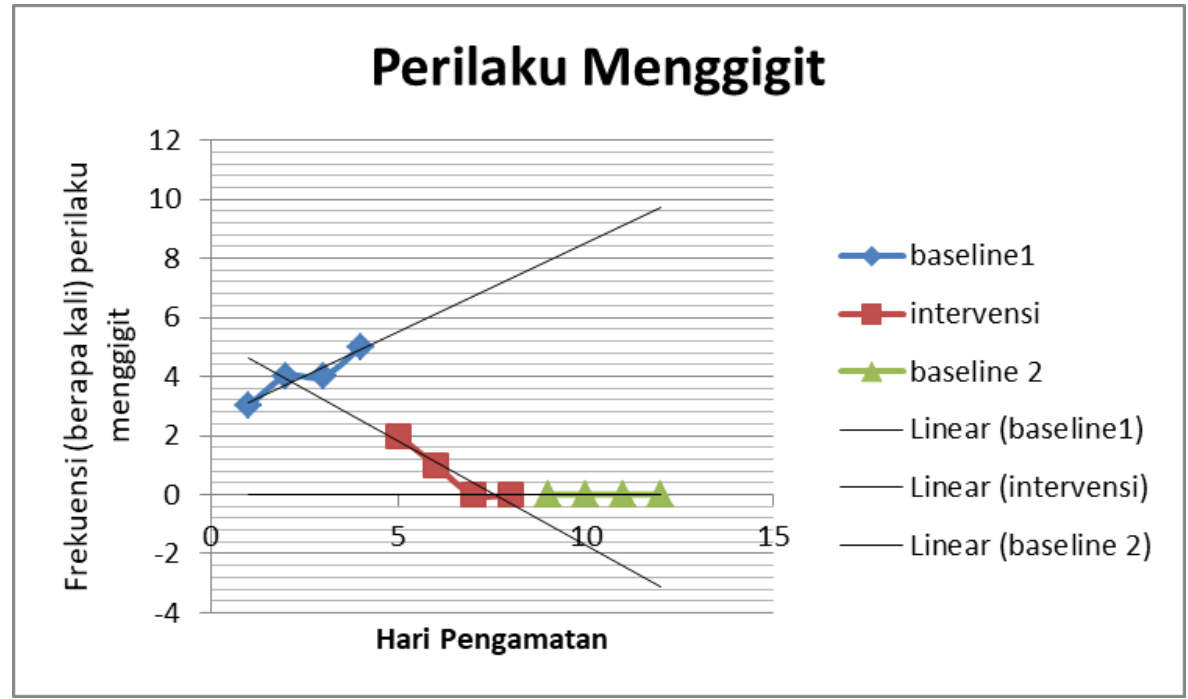

Sumber : Data Primer, 2021.

Gambar 3. Analisis visual perilaku menggigit subjek fase A1, B, A2

Berdasarkan Gambar 1 sampai 3 menunjukkan garis grafik menurun. Artinya, frekuensi perilaku menendang, memukul, maupun menggigit yang muncul pada subjek terus mengalami penurunan. Berikut hasil analisis visual dalam kondisi dan analisis visual antar kondisi pada perilaku menendang, memukul, dan menggigit subjek.

Tabel 2. Hasil analisis visual dalam kondisi perilaku menendang

\begin{tabular}{llll}
\hline \multicolumn{1}{c}{ Kondisi } & \multicolumn{1}{c}{ A1 } & \multicolumn{1}{c}{ B } & A2 \\
\hline Panjang Kondisi & 4 & 4 & 4 \\
\hline Estimasi Kecenderungan Arah & \multicolumn{1}{c}{ Tidak stabil } & Tidak stabil (50\%) & Tidak stabil (0\%) \\
\hline Kecenderungan Stabilitas & $(75 \%)$ & - & - \\
\hline Kecenderungan Jejak & - & Variable & Variable \\
\hline Level Stabilitas dan Rentang & Variable & $1.7-2.2$ & $0.1-0.3$ \\
\hline Level Perubahan & $4.3-5.1$ & $2.2-1.7=0.45$ & $0.3-0.1=0.15$ \\
& $5.1-4.3=0.75$ & Fase intervensi & Fase setelah \\
& Fase baseline & terjadi perubahan & intervensi terjadi \\
& terjadi & & perubahan \\
\hline
\end{tabular}

Sumber : Data Primer, 2021.

Tabel 3. Hasil analisis visual antar kondisi perilaku menendang

\begin{tabular}{llll}
\hline \multicolumn{2}{c}{ Perbandingan Kondisi } & $\mathrm{B} / \mathrm{A} 1$ & $\mathrm{~A} / \mathrm{B}$ \\
\hline Jumlah variable yang diubah & 1 & & \\
\hline $\begin{array}{l}\text { Perubahan kecenderungan arah dan } \\
\text { efeknya }\end{array}$ & - & - & - \\
\hline Perubahan kecenderungan Stabilitas & Variable ke variable & Variable ke variabel \\
\hline Perubahan level & $4-1=3$ & $1-1=0$ \\
\hline Presentase Overlap & $0 \%$ & $0 \%$ \\
\hline Sumber: Data Primer, 2021. & &
\end{tabular}


Table 4. Hasil analisis visual dalam kondisi perilaku memukul

\begin{tabular}{llll}
\hline \multicolumn{1}{c}{ Kondisi } & \multicolumn{1}{c}{ A1 } & B & A2 \\
\hline Panjang Kondisi & 4 & 4 & 4 \\
\hline Estimasi Kecenderungan Arah & & & Stabil (100\%) \\
\hline Kecenderungan Stabilitas & $\begin{array}{l}\text { Tidak stabil } \\
(25 \%)\end{array}$ & Tidak stabil (0\%) & S \\
\hline Kecenderungan Jejak & + & - & Stabil \\
\hline Level Stabilitas dan Rentang & Variable & Variable & $0-0$ \\
\hline Level Perubahan & $5.7-6.7$ & $1.1-1.4$ & $0-0=0$ \\
& $6.7-5.7=1$ & $1.4-1.1=0.3$ & Fase setelah \\
& Fase baseline & Fase intervensi & intervensi tidak \\
& terjadi & terjadi perubahan & terjadi \\
& perubahan & & perubahan \\
\hline
\end{tabular}

Sumber : Data Primer, 2021.

Tabel 5. Hasil analisis visual antar kondisi perilaku memukul

\begin{tabular}{|c|c|c|}
\hline Perbandingan Kondisi & $\mathrm{B} / \mathrm{A} 1$ & $\mathrm{~A} 2 / \mathrm{B}$ \\
\hline Jumlah variable yang diubah & 1 & 1 \\
\hline $\begin{array}{l}\text { Perubahan kecenderungan arah dan } \\
\text { efeknya }\end{array}$ & 7 & 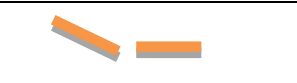 \\
\hline & + & $=$ \\
\hline Perubahan kecenderungan Stabilitas & Variable ke variable & Variable ke stabil \\
\hline Perubahan level & $7-2=5$ & $1-0=1$ \\
\hline Presentase Overlap & $0 \%$ & $0 \%$ \\
\hline
\end{tabular}

Sumber : Data Primer, 2021.

Tabel 6. Hasil analisis visual dalam kondisi perilaku menggigit

\begin{tabular}{|c|c|c|c|}
\hline Kondisi & A1 & B & $\mathrm{A} 2$ \\
\hline Panjang Kondisi & 4 & 4 & 4 \\
\hline Estimasi Kecenderungan Arah & 2 & & 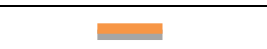 \\
\hline Kecenderungan Stabilitas & $\begin{array}{l}\text { Tidak stabil } \\
(50 \%)\end{array}$ & Tidak stabil (0\%) & Stabil $(100 \%)$ \\
\hline Kecenderungan Jejak & + & - & $=$ \\
\hline Level Stabilitas dan Rentang & $\begin{array}{l}\text { Variable } \\
3.6-4.3\end{array}$ & $\begin{array}{l}\text { Variable } \\
0.6-0.9\end{array}$ & $\begin{array}{l}\text { Stabil } \\
0-0\end{array}$ \\
\hline Level Perubahan & $\begin{array}{l}4.3-3.6=0.75 \\
\text { Fase baseline } \\
\text { terjadi } \\
\text { perubahan }\end{array}$ & $\begin{array}{l}0.9-0.6=0.3 \\
\text { Fase intervensi } \\
\text { terjadi perubahan }\end{array}$ & $\begin{array}{l}0-0=0 \\
\text { Fase setelah } \\
\text { intervensi tidak } \\
\text { terjadi } \\
\text { perubahan }\end{array}$ \\
\hline
\end{tabular}

Sumber : Data Primer, 2021. 
Tabel 7. Hasil analisis visual antar kondisi perilaku menggigit

\begin{tabular}{lll}
\hline Perbandingan Kondisi & B/A1 & A2/B \\
\hline Jumlah variable yang diubah & 1 & 1 \\
\hline $\begin{array}{l}\text { Perubahan kecenderungan arah dan } \\
\text { efeknya }\end{array}$ & $+\quad-$ & $-=$ \\
& $+\quad 5-2=3$ & Variable ke stabil \\
\hline Perubahan kecenderungan Stabilitas & Variable ke variable & $0=0$ \\
\hline Perubahan level & $5-2=0$ \\
\hline Presentase Overlap & $0 \%$ & 0
\end{tabular}

Sumber : Data Primer, 2021.

Berdasarkan hasil kecenderungan jejak data dan kecenderungan arah dan efeknya dapat diketahui jika perilaku menendang, memukul, dan menggigit subjek diawal cenderung naik kemudian menurun setelah turun perilaku agresif subjek cenderung tidak muncul kembali. Perubahan kecenderungan arah pada perilaku menendang, memukul, dan menggigit mengalami perubahan menurun dapat dilihat pada table dan grafik. Berdasarkan hasil dari perubahan level diketahui selisih dari perilaku menendang, memukul, dan mengigit subjek, hal ini menunjukkan adanya perubahan penurunan perilaku melalui diberikannya intervensi kepada subjek.

Hasil overlap pada analisis visual antar kondisi perilaku menendang, memukul, dan menggigit 0\%. Prosentase overlap yang kecil, artinya ada pengaruh intervensi berupa social story untuk menurunkan target perilaku (Sunanto dkk., 2005). Hal ini dapat dikatakan jika intervensi berupa social story berpengaruh untuk menurunkan target behavior subjek yaitu perilaku agresif berupa perilaku menendang, memukul, dan menggigit.

\section{Pembahasan}

Berdasarkan hasil penelitian dapat dilihat jika subjek mengalami penurunan perilaku agresif. Perilaku agresif yang mengalami penurunan itu antara lain perilaku menendang, memukul, dan menggigit. Perilaku agresif tersebut turun selama 12 sesi pertemuan melalui social story. Berdasarkan hasil penelitian, social story efektif untuk menurunkan perilaku agresif anak dengan retardasi mental. Hal ini sejalan dengan penelitian Gül (2016) diketahui bahwa penggunaan intervensi yang terdiri dari pemodelan video yang disajikan oleh komputer dan cerita sosial (social stories) kepada individu dengan disabilitas intelektual efektif untuk meningkatkan kemampuan dalam keterampilan sosial. Hasil penelitian menunjukkan bahwa individu dengan disabilitas intelektual memperoleh ketrampilan sosial dengan akurasi $100 \%$, mempertahankan ketrampilan sosial dari waktu ke waktu, dan dapat digeneralisasikan di banyak setting, kondisi, dan orang-orang (Gül, 2016).

Subjek dalam penelitian ini adalah anak dengan retardasi mental ringan. Anak dengan retardasi mental memiliki masalah dalam kemampuan social yang membutuhkan asesmen terkait perilakunya dan butuh untuk diberikan program intervensi (Hosseinkhanzadeh, 2014). Kemampuan interaksi social dari anak dengan retardasi mental juga memiliki kaitan dengan kurangnya kemampuan komunikasi dengan lingkungan sehingga membuat masalah pada interaksi sosialnya dan memunculkan masalah perilaku (Suchyadi et al., 2018). Penelitian Ageranioti-Bélanger dkk. (2012) menjelaskan jika masalah perilaku yang muncul pada anak dengan intelektual disabilitas salah satunya adalah perilaku agresif. Perilaku agresif yang dilakukan oleh anak dengan retardasi mental disebabkan karena deficit yang ia miliki, dan membutuhkan untuk penanganan professional (Brulle, 1981).

Efektivitas pemberian social story mampu menurunkan perilaku agresif subjek disekolah. Hal ini dapat diamati berdasarkan penurunan skor yang diperoleh subjek berkaitan dengan frekuensi perilaku agresif yang muncul pada kondisi A-B-A'. Pada tiap sesi intervensi, subjek cenderung mengalami penurunan perilaku agresif. Hasil kecenderungan jejak data dan kecenderungan arah dan efeknya dapat diketahui jika perilaku menendang, memukul, dan menggigit subjek diawal cenderung naik kemudian menurun setelah turun perilaku agresif subjek cenderung tidak muncul kembali. Perubahan kecenderungan arah pada perilaku menendang, memukul, dan menggigit mengalami perubahan menurun dapat dilihat pada table dan grafik.

Berdasarkan hasil dari perubahan level diketahui selisih dari perilaku menendang, memukul, dan mengigit subjek, hal ini menunjukkan adanya perubahan penurunan perilaku melalui diberikannya 
intervensi kepada subjek. Metode yang sedang terkenal dalam dunia Pendidikan berkebutuhan khusus adalah menggunakan cerita sosial (Tarnai \& Wolfe, 2008). Sebuah cerita sosial (social story) merupakan cara pengajaran yang tepat untuk mengajarkan ketrampilan sosial dan perilaku anak atau yang berkaitan dengan hambatan yang melekat pada individu dengan hambatan intelektual. Penelitian Soetikno dkk. (2017) menyampaikan cerita mampu memberikan pengaruh positif pada kemampuan adaptif anak dengan keterbelakangan mental.

Sebuah cerita sosial terdiri dari cerita pendek dengan karakteristik spesifik untuk menggambarkan suatu situasi sosial, konsep, atau ketrampilan sosial. Pada awalnya social story dikembangkan oleh Gray pada tahun 1991 untuk mengajarkan anak dengan spektrum autis bagaimana bermain dengan teman sebaya, yang bertujuan untuk meningkatkan kemampuan interaksi sosial dengan orang lain (Tarnai \& Wolfe, 2008). Dengan melatihkan situasi-situasi yang biasanya dapat mengakibatkan kebingungan dan kesalahpahaman, anak akan mampu memahami respons yang tepat dengan lebih baik Soetikno dkk. (2017). Media cerita sosial terdiri dari beberapa kalimat deksriptif, perpektif, direktif, kontrol dan afirmatif yang berfungsi menjelaskan fakta-fakta dari sebuah gambar yang akan diberikan. Adapun yang dimaksud dengan kalimat deskriptif adalah menjelaskan munculnya situasi, tempat dimana peristiwa terjadi, siapa yang berpartisipasi, peristiwa apa yang terjadi atau individu mengapa harus berperilaku demikian. Pada kalimat deskriptif cenderung menjelaskan pemikiran orang lain, motivasi, dan keyakinan. Sedangkan kalimat deskriptif merupakan tindakan secara langsung yang diharapkan dilakukan pada anak (Quinbach, dkk 2008).

\section{Kesimpulan}

Social story dapat menurunkan perilaku agresif anak dengan retardasi mental. Berdasarkan analisis grafik membuktikan terdapat perbedaan perilaku yang muncul sebelum dan sesudah intervensi berupa social story. Grafik yang mengalami penurunan serta kecilnya overlap membuktikan jika intervensi pemberian social story mampu menurunkan perilaku agresif subjek.

Anjuran pada riset berikutya dengan tema yang sama, ialah: subjek riset yang digunakan pada riset ini merupakan anak dengan retardasi mental tunggal, bisa digunakan subjek yang lebih variatif pada segi budaya ataupun usia. Dianjurkan kepada orang tua serta guru maupun pihak sekolah supaya melakukan pemberian social story untuk mengurangi perilaku agresif pada anak dengan retardasi mental.

\section{Daftar Pustaka}

Ageranioti-Bélanger, S., Brunet, S., D’Anjou, G., Tellier, G., Boivin, J., \& Gauthier, M. (2012). Behaviour disorders in children with an intellectual disability. Paediatrics and Child Health, 172), 84-88. https://doi.org/10.1093/pch/17.2.84

Ali, N. H., \& Utami, D. S. (2013). Efektivitas Buku "Pelangi Hatiku" Dalam Menurunkan Agresi Siswa Sekolah Dasar. Jurnal Intervensi Psikologi (JIP), 5(1), 59-74.

https://doi.org/10.20885/intervensipsikologi.vol5.iss1.art4

Association, A. P. (n.d.). Diagnostic and statictical manual of mental disorders. In DSM-5 (5th ed.). American Psychiatric Publishing.

Berkowitz, L. (n.d.). Aggression It's Causes, Consequences And Control. Mcgraw Hill.

Brulle, A. R. (1981). Handbook of behavior modification with the mentally retarded. Plenum Press.

Gül, S. O. (2016). The combined use of video modeling and social stories in teaching social skills for individuals with intellectual disability. Kuram ve Uygulamada Egitim Bilimleri, 16(1), 83-107. https://doi.org/10.12738/estp.2016.1.0046

Hallahan, D. P. da. K., \& M, J. (n.d.). Exceptional Children: An Introduction to Special Eduction (10th ed.). Allyn and Bacon.

Hosseinkhanzadeh, A. A. (2014). Identification of Social Skills Deficits in Students with Mental Retardation. International Journal of Psychology and Behavioral Research, 3(5), 402-411. http://www.ijpbrjournal.com

Kokko, K., Pulkkinen, K. K., Huesmann, L. R., Dubow, E. F., \& Boxer, P. (n.d.). Intensity of Aggression in Childhood as Predictor of Different Forms of Adults Aggression: A Two-Country (Finland and the United States. Analysis. Journal of Research on Adolescence, 19(1), 9-34. 
Latipun. (n.d.). Psikologi Eksperimen. UMM Press.

Mangunsong, F. (n.d.). Psikologi dan Pendidikan Anak Berkebutuhan Khusus jilid kesatu. LPSP3 UI.

Papalia, E. D., S., O. W., \& R, F. D. (n.d.). Psikologi Perkembangan. Kencana.

Quirnbach, L., M., L., \& Alan., F. M. (n.d.). Social Stories: Mechanism of effectiveness in increasing game play skills in children diagnosed with autis spectrum disorder using a pretest posttest repeated measure randomized control group design. Journal Autism Development Disorder.

Soetikno, N., Verauli, R., \& Agustina, -. (2017). Pengaruh Mendongeng Terhadap Kemampuan Adaptif Anak Keterbelakangan Mental. EduHumaniora / Jurnal Pendidikan Dasar Kampus Cibiru, 9(2), 84. https://doi.org/10.17509/eh.v9i2.7033

Suchyadi, Y., Ambarsari, Y., \& Sukmanasa, E. (2018). Analysis of Social Interaction of Mentally Retarded Children. Jhss (Journal of Humanities and Social Studies), 2(2), 17-21. https://doi.org/10.33751/jhss.v2i2.903

Sunanto, J., Takeuchi, K., \& Nakata, H. (n.d.). Pengantar Penelitian Dengan Subjek Tunggal. Alfabeta.

Tarnai, B., \& Wolfe, P. S. (n.d.). Social Stories for sexuality education for persons with autism/pervasive development disorder. Department of educational and school psychology and special education. Original Paper, 26, 29-36. 